\title{
Prevalence and Infection Intensity of Zoonotic Trematode Metacercariae in Fish from Soyang-cheon (Stream), in Wanju-gun, Jeollabuk-do, Korea
}

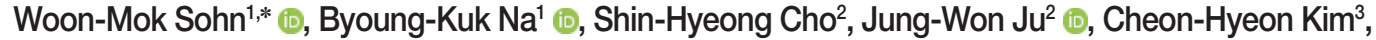 \\ Min-Ah Hwang ${ }^{3}$, Kyeong-Woo No ${ }^{3}$, Jong-Ho Park ${ }^{3}$ \\ 'Department of Parasitology and Tropical Medicine, and Institute of Health Sciences, Gyeongsang National University School of Medicine, \\ Jinju 52727, Korea; '2Division of Vectors and Parasitic Diseases, Korea Disease Control and Prevention Agency, Osong 28159, Korea; \\ ${ }^{3}$ Division of Microorganism, Jeollabuk-do Institute of Health and Environment, Imsil 55928, Korea
}

\begin{abstract}
We surveyed on the infection status of zoonotic trematode metacercariae (ZTM) in freshwater fishes from Soyang-cheon (a branch stream of Mangyeong-gang) in Wanju-gun, Jeollabuk-do, the Republic of Korea. A total of 927 fishes were individually examined with the artificial digestion method during 2013-2015 (462 fish in 15 spp.) and 2018-2019 (465 fish in 25 spp.). Clonorchis sinensis metacercariae were detected in 207 (31.4\%) out of 659 fishes in 14 positive fish species (PFS), and their mean intensity was 114 per fish infected (PFI). Metagonimus spp. metacercariae were found in 302 (37.4\%) out of 808 fishes in 21 PFS, and their mean intensity was 12 PFI. Centrocestus armatus metacercariae were detected in $222(59.0 \%)$ out of 376 fishes in 12 PFS, and their mean intensity was 383 PFI. Echinostoma spp. metacercariae were found in 139 (22.1\%) out of 628 fishes in 10 PFS, and their mean intensity was 7 PFI. Clinostomum complanatum metacercariae were detected in $14(6.5 \%)$ out of 214 fishes in 4 PFS, and their mean intensity was 2.4 PFI. Metorchis orientalis metacercariae were detected in 36 (13.5\%) out of 267 fishes in 5 PFS, and their mean intensity was $4.3 \mathrm{PFI}$. Conclusively, the prevalence and infection intensity of ZTM is generally not so high in fishes from Soyang-cheon. However, those of $C$. sinensis metacercariae are more or less higher in 2 fish species, Pungtungia herzi and Sarcocheilichthys variegatus wakiyae.
\end{abstract}

Key words: Clonorchis sinensis, Metagonimus spp. Centrocestus armatus, Echinostoma sp., Clinostomum complanatum, Metorchis orientalis, zoonotic trematode metacercaria, Soyang-cheon, Mangyeong-gang, Korea

\section{INTRODUCTION}

Infections of fishborne zoonotic trematodes (FZT) including Clonorchis sinensis affect the health of more than 20 million people around the world. FZT provoke remarkable morbidity and cause serious damage to fish aquaculture in developing countries. In the Republic of Korea (Korea), FZT infection is one of the important public health problems [1]. A team (Division of Vectors and Parasitic Diseases) of Korea DCPA (Korea Disease Control and Prevention Agency) has performed the control project for zoonotic trematode infections in some endemic areas in Korea. The main control target of the project

\footnotetext{
• Received 18 April 2021, revised 26 May 2021, accepted 30 May 2021.

*Corresponding author (wmsohn@gnu.ac.kr)

(c) 2021, Korean Society for Parasitology and Tropical Medicine

This is an Open Access article distributed under the terms of the Creative Commons Attribution Non-Commercial License (https://creativecommons.org/licenses/by-nc/4.0) which permits unrestricted non-commercial use, distribution, and reproduction in any medium, provided the original work is properly cited.
}

was clonorchiasis, C. sinensis infection. Therefore, the team of Korea DCPA has continuously paid attentions and made efforts to decrease the endemicity of clonorchiasis in endemic areas, especially, riverside areas of major rivers, in southern regions of Korea [2-5].

Freshwater fishes, the infection sources of FZT, have been also examined by the co-working group of Korea DCPA to reveal the epidemiological situations in several water systems of major rivers in Korea [6-16]. The infections of digenetic trematode metacercariae (DTM) including C. sinensis were surveyed in freshwater fish from the water systems of Hantan-gang (gang means river) and Imjin-gang in northern regions of Korea [8]. The infection status of $C$. sinensis metacercariae (CsMc) was investigated in freshwater fishes from the water systems of Seomjin-gang and Tamjin-gang $[9,10]$. The infection characteristics of CsMc were also investigated in freshwater fish from 3 highly endemic sites (branch streams of Nakdong-gang), Wicheon (cheon means stream), Yongjeon-cheon and Yang- 
cheon, in Gyeongsangbuk-do and Gyeongsangnam-do, Korea [11-13]. Recently, Sohn et al. [14,15] reported the infection status with ZTM in fishes from Geum-gang and with DTM in fishes from coastal lakes in Gangwon-do, Korea. Sohn and $\mathrm{Na}$ [16] described the infection status of DTM in freshwater fishes from 2 visiting sites, Junam-jeosuji (jeosuji means reservoir) and Woopo-neup (neup means swamp), of migratory birds in Gyeongsangnam-do, Korea.

Soyang-cheon is a branch stream of Mangyeong-gang in Jeollabuk-do, Korea. It flows from the Mandeok-san (san means mountain), unites with some streams at Wanju-gun and Jeonju-si, Jeollabuk-do, forms main river, Mangyeong-gang, and reaches the Yellow Sea [17]. On the other hand, epidemiological studies have been performed to investigate the infection status of CsMc and DTM in fishes from Mangyeong-gang $[18,19]$. However, these studies were performed at early 1980 's, and the large-scale survey on the infection status of ZTM has not been conducted yet in this region. Therefore, in this study, we investigated the infection status of ZTM in freshwater fishes from Soyang-cheon in Wanju-gun, Jeollabuk-do during 2 survey periods, the former (2013-2015) and the latter periods (2018-2019).

\section{MATERIALS AND METHODS}

We collected total 927 freshwater fishes (30 species) in Soyang-cheon (a branch stream of Mangyeong-gang) located in Wanju-gun (Latitude: 36.114265; Longitude: 127.587748), Jeollabuk-do, Korea (2013-2015 and 2018-2019).

Total 462 freshwater fish (15 species) were examined for 3 years (2013-2015). Fishes (No. of fish) examined were Pungtungia herzi (98), Zacco temminckii (60), Pseudogobio esocinus (55), Coreoperca herzi (53), Odontobutis platycephala (49), Hemibarbus longirostris (42), Carassius auratus (30), Zacco platypus (20), Pseudobagrus koreanus (15), Acheilognathus yamatsutae (13), Acheilognathus lanceolatus (10), Sarcocheilichthys variegatus (7), Acanthorhodeus macropterus (6), Acanthorhodeus gracilis (3), Opsariichthys uncirostris (1).

Total 465 freshwater fish (25 species) were examined for 2 years (2018-2019). Fishes (No. of fish) examined were $P$. herzi (87), Z. platypus (80), P. esocinus (68), O. platycephala (57), $H$. longirostris (52), Zacco koreanus (28), C. herzi (23), Gnathopogon strigatus (11), Pseudobagrus fulvidraco (10), P. koreanus (10), Iksookimia longicorpa (9), Koreocobitis naktongensis (4), Coreoleuciscus splendidus (4), Squalidus chankaensis (3), Hypomesus nippon- ensis (3), Acheilognathus koreensis (3), S. variegatus (2), Siniperca scherzeri (2), C. auratus (2), Misgurnus anguillicaudatus (2), Micropterus salmoides (1), Z. temminckii (1), Acheilognathus rhombeus (1), Rhynchocypris oxycephalus (1), Cobitis sinensis (1).

All collected fishes with ice were transferred to the laboratory of Department of Parasitology and Tropical Medicine, Gyeongsang National University College of Medicine, Jinju, Korea. All fishes were individually treated with the conventional artificial digestion method after identification of fish species [20]. Each species of ZTM were separately collected viewing from the general feature, and were counted to get hold of the prevalence (\%) and intensity of infection (No. of ZTM per fish infected) by fish species [21,22].

\section{RESULTS}

The metacercariae of C. sinensis (CsMc) were detected in 207 (31.4\%) out of 659 fishes in 14 positive fish species (PFS), and their infection intensity was 114 per fish infected (PFI). The prevalences were $48.1 \%$ and $21.8 \%$, but mean intensities were 22 and 230 PFI in the former (2013-2015) and the latter periods (2018-2019). The infection status of CsMc by the fish species and survey period was revealed in Table 1 in detail. The infection status with CsMc by the survey year was detailedly shown in Supplementary Table S1. Metagonimus spp. metacercariae (MsMc) were found in 302 (37.4\%) out of 808 fishes in $21 \mathrm{PFS}$, and their infection intensity was 12 PFI. The prevalences were $39.1 \%$ and $35.9 \%$, and mean intensities were 4 and 19 PFI in the former and latter periods. The infection status of MsMc by the fish species and survey period was detailedly designated in Table 2.

The metacercariae of Centrocestus armatus (CaMc) were detected in 222 (36.5\%) of 608 fishes in 12 PFS and their infection intensity was 383 PFI. The overall infection status of CaMc by the fish species was shown in Table 3 in detail. Echinostoma spp. metacercariae (EsMc) were found in 139 (20.7\%) out of 671 fishes in 10 PFS and their infection intensity was 7 PFI. The overall infection status of EsMc by the fish species was detailedly revealed in Table 4. The metacercariae of Clinostomum complanatum (CcMc) were detected in $14(6.5 \%)$ out of 216 fishes in 4 PFS and their infection intensity was 2.4 PFI. The overall infection status of CcMc by the fish species was designated in Table 5 in detail. The metacercariae of Metorchis orientalis (MoMc) were found in 36 (11.2\%) out of 322 fishes in 5 PFS and their infection intensity was 4.3 PFI. The overall 
Table 1. Infection status of Clonorchis sinensis metacercariae (CsMc) in fish from Soyang-cheon (stream) in Wanju-gun, Jeollabuk-do, Korea

\begin{tabular}{|c|c|c|c|c|}
\hline \multirow{2}{*}{ Year and fish sp. } & \multirow{2}{*}{ No. of fish examined } & \multirow{2}{*}{ No. (\%) of fish infected } & \multicolumn{2}{|c|}{ No. of CsMc detected } \\
\hline & & & Range & Average \\
\hline \multicolumn{5}{|l|}{$2013-2015$} \\
\hline Pungtungia herzi & 98 & $97(99.0)$ & $1-225$ & 25.8 \\
\hline Pseudogobio esocinus & 55 & $2(3.6)$ & - & 1.0 \\
\hline Hemibarbus longirostris & 42 & $3(7.1)$ & - & 1.0 \\
\hline Zacco platypus & 20 & $2(10.0)$ & - & 1.0 \\
\hline Acheilognathus yamatsutae & 13 & $4(30.8)$ & $1-2$ & 1.3 \\
\hline Sarcocheilichthys variegatus & 7 & $7(100)$ & $1-19$ & 7.3 \\
\hline Acanthorhodeus macropterus & 6 & $1(16.7)$ & - & 1.0 \\
\hline Subtotal & 241 & $116(48.1)$ & $1-225$ & 22.2 \\
\hline \multicolumn{5}{|l|}{ 2018-2019 } \\
\hline Pungtungia herzi & 87 & $58(66.7)$ & $1-2,310$ & 351 \\
\hline Zacco platypus & 80 & $4(5.0)$ & $1-7$ & 3.3 \\
\hline Pseudogobio esocinus & 68 & $11(16.2)$ & $1-5$ & 1.7 \\
\hline Odontobutis platycephala & 57 & $1(1.8)$ & - & 1.0 \\
\hline Hemibarbus longirostris & 52 & $3(5.8)$ & $2-6$ & 3.7 \\
\hline Zacco koreanus & 28 & $1(3.6)$ & - & 1.0 \\
\hline Coreoperca herzi & 23 & $1(4.4)$ & - & 1.0 \\
\hline Gnathopogon strigatus & 11 & $5(45.5)$ & $1-2$ & 1.6 \\
\hline Coreoleuciscus splendidus & 4 & $1(25.0)$ & - & 1.0 \\
\hline Squalidus chankaensis & 3 & $3(100)$ & $3-6$ & 4.7 \\
\hline Acheilognathus koreensis & 3 & $1(33.3)$ & - & 11.0 \\
\hline Sarcocheilichthys variegatus & 2 & $2(100)$ & $75-433$ & 254 \\
\hline Subtotal & 418 & $91(21.8)$ & $1-2,310$ & 230 \\
\hline Total & 659 & $207(31.4)$ & $1-2,310$ & 113.6 \\
\hline
\end{tabular}

infection status of MoMc by the fish species was detailedly shown in Table 6.

\section{DISCUSSION}

In this study, more than 6 species of ZTM, i.e., C. sinensis, Metagonimus spp., C. armatus, Echinostoma spp., C. complanatum and M. orientalis, were detected in fishes from Soyangcheon in Wanju-gun, Jeollabuk-do, Korea. Their individual prevalences and infection intensities were relatively not so high when we compared with those of some other regions [616]. However, the infection intensity with CsMc was over 110 in the latter period (2018 and 2019), and especially, those in 2 fish species, i.e., P. herzi and S. variegatus wakive, were 351 and 254 PFI. On the other hand, it has been known that the intensity of infection increases in proportion to the prevalence. However, the prevalence (48.1\%) of CsMc in the former period was much higher than that $(21.8 \%)$ in the latter period, but the intensity of infection was much higher in the latter period (230 PFI) than that in the former period (22 PFI). In case of index fish, the striped shinner, $P$. herzi, the prevalence was also higher in the former period but the intensity of infection was much higher in the latter period. There are obvious discrepancies between the prevalence and intensity of infection on the CsMc infections in this study. It may be the reason why the endemicities with CsMc in 2 fish species, $P$. herzi and $S$. variegatus wakive, were relatively high in 2019, meanwhile those in all positive fish species including $P$. herzi were very low in 2018 (Supplementary Table S1).

A total of 927 fish in 30 species were examined in this study. Among them, Pungtungia herzi (20.0\%) was most dominantly examined and followed by P. esocinus (13.3\%), O. platycephala (11.4\%), Z. platypus (10.8\%), H. longirostris (10.1\%), C. herzi (8.2\%), Z. temminckii (6.6\%), C. auratus (3.5\%), Z. koreanus (3.0\%), and P. koreanus (2.7\%). Only 10 fish species were examined more than 25 fish individuals and remain 20 fish species were examined less than 4.4 fish in average respectively. Rhee et al. [18,19] examined total 380 fish in 32 species collected from Mangyeong-gang. Among them, total 11 fish species, i.e., Carassius carassius (C. auratus) (15.8\%), Cultriculus ei- 
Table 2. Infection status of Metagonimus spp. metacercariae (MsMc) in fish from Soyang-cheon (stream) in Wanju-gun, Jeollabuk-do, Korea

\begin{tabular}{|c|c|c|c|c|}
\hline \multirow{2}{*}{ Year and fish sp. } & \multirow{2}{*}{ No. of fish examined } & \multirow{2}{*}{ No. (\%) of fish infected } & \multicolumn{2}{|c|}{ No. of MsMc detected } \\
\hline & & & Range & Average \\
\hline \multicolumn{5}{|l|}{$2013-2015$} \\
\hline Pungtungia herzi & 98 & $40(40.8)$ & $1-7$ & 2.0 \\
\hline Zacco temminckii & 60 & $35(58.3)$ & $1-27$ & 4.3 \\
\hline Pseudogobio esocinus & 55 & $16(29.1)$ & $1-22$ & 5.8 \\
\hline Odontobutis platycephala & 49 & $7(14.3)$ & $1-2$ & 1.1 \\
\hline Hemibarbus longirostris & 42 & $20(47.6)$ & $1-6$ & 2.6 \\
\hline Carassius auratus & 30 & $3(10.0)$ & $1-2$ & 1.3 \\
\hline Zacco platypus & 20 & $15(75.0)$ & $2-19$ & 9.0 \\
\hline Acheilognathus yamatsutae & 13 & $1(7.7)$ & - & 1.0 \\
\hline Sarcocheilichthys variegatus & 7 & $4(57.1)$ & $2-3$ & 2.5 \\
\hline Acanthorhodeus macropterus & 6 & $6(100)$ & $2-6$ & 4.3 \\
\hline Acanthorhodeus gracilis & 3 & $2(66.7)$ & $2-7$ & 4.5 \\
\hline Opsariichthys uncirostris & 1 & $1(100)$ & - & \\
\hline Subtotal & 384 & $150(39.1)$ & $1-27$ & 3.8 \\
\hline \multicolumn{5}{|l|}{ 2018-2019 } \\
\hline Pungtungia herzi & 87 & $12(13.8)$ & $1-12$ & 2.5 \\
\hline Zacco platypus & 80 & 65 (81.3) & $1-36$ & 8.7 \\
\hline Pseudogobio esocinus & 68 & $13(19.1)$ & $1-6$ & 1.8 \\
\hline Odontobutis platycephala & 57 & $14(24.6)$ & $1-6$ & 2.0 \\
\hline Zacco koreanus & 28 & 25 (89.3) & $1-890$ & 90.4 \\
\hline Hemibarbus longirostris & 52 & $4(7.7)$ & $1-3$ & 1.5 \\
\hline Coreoperca herzi & 23 & $2(8.7)$ & - & 1.0 \\
\hline Gnathopogon strigatus & 11 & $8(72.7)$ & $1-3$ & 1.5 \\
\hline Coreoleuciscus splendidus & 4 & $3(75.0)$ & $1-2$ & 1.3 \\
\hline Koreocobitis naktongensis & 4 & $1(25.0)$ & - & 1.0 \\
\hline Squalidus chankaensis & 3 & $1(33.3)$ & - & 2.0 \\
\hline Acheilognathus koreensis & 3 & 1 (33.3) & - & 1.0 \\
\hline Misgurnus anguillicaudatus & 2 & $1(50.0)$ & - & 1.0 \\
\hline Zacco temminckii & 1 & $1(100)$ & - & 3.0 \\
\hline Rhynchocypris oxycephalus & 1 & $1(100)$ & - & 2.0 \\
\hline Subtotal & 424 & $152(35.9)$ & $1-890$ & 19.3 \\
\hline Total & 808 & $302(37.4)$ & $1-890$ & 11.6 \\
\hline
\end{tabular}

Table 3. Overall infection status of Centrocestus armatus metacercariae (CaMc) in fish from Soyang-cheon (stream) in Wanju-gun, Jeollabuk-do, Korea

\begin{tabular}{|c|c|c|c|c|}
\hline \multirow{2}{*}{ Fish sp. } & \multirow{2}{*}{ No. of fish examined } & \multirow{2}{*}{ No. (\%) of fish infected } & \multicolumn{2}{|c|}{ No. of CaMc detected } \\
\hline & & & Range & Average \\
\hline Pseudogobio esocinus & 123 & $2(1.6)$ & - & 1.0 \\
\hline Odontobutis platycephala & 106 & $1(0.9)$ & - & 8.0 \\
\hline Zacco platypus & 100 & $100(100)$ & $2-5,845$ & 663 \\
\hline Hemibarbus longirostris & 94 & $9(9.6)$ & $1-14$ & 5.6 \\
\hline Coreoperca herzi & 76 & $8(10.5)$ & $1-52$ & 15.5 \\
\hline Zacco temminckii & 61 & $61(100)$ & $3-2,536$ & 250 \\
\hline Zacco koreanus & 28 & $28(100)$ & $2-472$ & 50.9 \\
\hline Sarcocheilichthys variegatus & 9 & $3(33.3)$ & $1-2$ & 1.7 \\
\hline Acanthorhodeus macropterus & 6 & $6(100)$ & $123-631$ & 293 \\
\hline Acanthorhodeus gracilis & 3 & $2(66.7)$ & $32-34$ & 33.0 \\
\hline Opsariichthys uncirostris & 1 & $1(100)$ & - & 2.0 \\
\hline Acheilognathus rhombeus & 1 & $1(100)$ & - & 13.0 \\
\hline Total & 608 & $222(36.5)$ & $1-5,845$ & 383 \\
\hline
\end{tabular}


Table 4. Overall infection status of Echinostoma spp. metacercariae (EsMc) in fish from Soyang-cheon (stream) in Wanju-gun, Jeollabukdo, Korea

\begin{tabular}{lcccc}
\hline & No. of fish examined & No. $(\%)$ of fish infected & \multicolumn{2}{c}{ No. of EsMc detected } \\
\cline { 4 - 5 } Fish sp. & 185 & $34(18.4)$ & Range & 1.4 \\
\hline Pungtungia herzi & 123 & $14(11.4)$ & $1-3$ & 3.3 \\
Pseudogobio esocinus & 106 & $69(65.1)$ & $1-107$ & 12.0 \\
Odontobutis platycephala & 94 & $2(2.1)$ & $1-17$ & 9.0 \\
Hemibarbus longirostris & 76 & $13(17.1)$ & $1-3$ & 1.4 \\
Coreoperca herzi & 61 & $2(3.3)$ & - & 1.0 \\
Zacco temminckii & 11 & $1(9.1)$ & - & 1.0 \\
Gnathopogon strigatus & 9 & $1(11.1)$ & - & 2.0 \\
Iksookimia longicorpa & 4 & $1(25.0)$ & $3-4$ & 1.0 \\
Koreocobitis naktongensis & 2 & $2(100)$ & $1-107$ & 3.5 \\
Misgurnus anguillicaudatus & 671 & $139(20.7)$ & & 7.0 \\
Total & & &
\end{tabular}

Table 5. Overall infection status of Clinostomum complanatum metacercariae (CcMc) in fish from Soyang-cheon (stream) in Wanju-gun, Jeollabuk-do, Korea

\begin{tabular}{lrrrr}
\hline \multirow{2}{*}{ Fish sp. } & No. of fish examined & No. (\%) of fish infected & \multicolumn{2}{c}{ No. of CcMc detected } \\
\cline { 4 - 5 } & & $11(5.9)$ & Range & 1.8 \\
\hline Pungtungia herzi & 185 & $1(7.7)$ & - & 9.0 \\
Acheilognathus yamatsutae & 13 & $1(11.1)$ & - & 2.0 \\
Sarcocheilichthys variegatus & 9 & $1(11.1)$ & - & 2.0 \\
Iksookimia longicorpa & 9 & $14(6.5)$ & $1-9$ & 2.4 \\
Total & 216 & & \\
\hline
\end{tabular}

Table 6. Overall infection status of Metorchis orientalis metacercariae (MoMc) in fish from Soyang-cheon (stream) in Wanju-gun, Jeollabuk-do, Korea

\begin{tabular}{lcccc}
\hline \multirow{2}{*}{ Fish sp. } & No. of fish examined & No. (\%) of fish infected & \multicolumn{2}{c}{ No. of MoMc detected } \\
\cline { 4 - 5 } & & $11(5.9)$ & Range & 1.3 \\
\hline Pungtungia herzi & 185 & $2(1.6)$ & - & 1.0 \\
Pseudogobio esocinus & 123 & $1(11.1)$ & - & 1.0 \\
Iksookimia longicorpa & 9 & $2(50.0)$ & $5-85$ & 45.0 \\
Koreocobitis naktongensis & 4 & $1(100)$ & - & 10.0 \\
Cobitis sinensis & 1 & $36(11.2)$ & $1-85$ & 4.3 \\
Total & 322 & & \\
\hline
\end{tabular}

genmanni (Hemiculter leucisculus) (8.7\%), Pseudorasbora parva (8.2\%), Aphyocypris chinensis (7.6\%), Z. platypus (7.4\%), A. gracilis (6.3\%), Gnathopogon majimae (Squalidus gracilis majimae) (5.0\%), Coreoleuciscus splendidus (5.0\%), Pseudoperilampus uyekii (Rhodeus uyekii) (4.5\%), Rhodeus ocellatus (4.0\%), and Gnathopogon coreanus (Squalidus japonicas coreanus) (4.0\%), were examined more than 15 fish individuals. Major fish species in this study is completely different from that in Rhee et al. $[18,19]$ except for C. auratus. It is suggested that the fish ecology has been changed for more than 30 years in Mangyeong-gang.

The metacercariae of C. sinensis (CsMc) were detected in 207
(31.4\%) out of 659 fishes in 14 (46.7\%) PFS, and their infection intensity was 114 PFI in this study. However, Rhee et al. [18] found CsMc in 93 (59.2\%) out of 157 fishes in 12 (37.5\%) PFS, with the infection intensity of 42 PFI. Among 12 fish species with CsMc in Rhee et al. [18], false dace, Pseudorasbora parva, was the most prevalent (96.8\%) with the highest intensity of infection (119 CsMc PFI). Meanwhile, total 4 out of 8 P. herzi examined were infected with $5 \mathrm{CsMc}$ in average. At that time, P. parva was most susceptible fish with CsMc and regarded as the index fish host in clonorchiasis epidemiology. In this study, no $P$. parva was examined at all, but $P$. herzi was 
most dominantly examined as the index fish host for clonorchiasis epidemiology.

In this study, Metagonimus spp. metacercariae (MsMc) were detected in 302 (37.4\%) out of 808 fish in PFS, and their infection intensity was about 12 PFI. In case of rasborinid fish species, Zacco spp. and Opsariichthys uncirostris, the prevalence with MsMc was $74.6 \%$ and the intensity of infection was about 22 PFI. Rhee et al. [19] detected MsMc in 164 (43.2\%) out of 380 fish examined from Mangyeong-gang, the same river in this study, in 1983. Recently, Sohn et al. [23] surveyed the infection status of MsMc in fishes from Seomjin-gang and Tamjin-gang. They reported 55.4\% and 57.7\% prevalences, and 96 and $138 \mathrm{MsMc}$ intensities in fishes from 2 rivers respectively. In the rasborinid fish from the water systems of Hantan-gang and Imjin-gang, MsMc prevalences were $73.9 \%$ and $72.1 \%$, and MsMc intensities were 43 and 19 PFI [8]. From the findings of previous studies, we can suppose that the endemicity with MsMc in this study is much lower than those in Seomjingang and Tamjin-gang, and similar with those in Hantan-gang and Imjin-gang.

Rhee et al. [19] detected CaMc in 7 fish species, i.e., A. chinensis, C. auratus, C. splendidus, Microphysogobio yaluensis, $R$. uyekii, P. parva, and Z. platypus, from Mangyeong-gang in Jeollabuk-do, Korea. They checked the prevalence and intensity of infection with the muscle compression method, and the prevalence and intensity of infection with CaMc were very low. In this study, CaMc were detected from 222 (36.5\%) out of 608 fishes in 12 positive species, i.e., Z. platypus, Z. temminckii, Z. koreanus, O. uncirostris, P. esocinus, H. longirostris, S. variegatus, A. macropterus, A. gracilis, A. rhombeus, O. platycephala, and C. her$z i$, and the mean intensity of infection was 383 PFI. Moreover, in the most susceptible fish hosts of CaMc, 3 species of chub, $Z$. platypus, $Z$. temminckii, and $Z$. koreanus, the prevalence was $100 \%$, but the mean intensity of infection was 439 PFI. The endemicity of CaMc in chubs from Soyang-cheon is similar with that from Seomjin-gang, but it is much lower than that from water systems of other major rivers in Korea [24].

Infection status of Echinostoma spp. metacercariae (EsMc) was not so high in fish from Soyang-cheon in this study. They were detected in 139 (20.7\%) out of 671 fish in 10 positive species, and their mean intensity of infection was 7 PFI. However, in Korean dark sleeper, O. platycephala, their prevalence was $65.1 \%$ and the mean intensity of infection was 12.0 PFI. Recently, Sohn et al. [14] reported $100 \%$ prevalence and about 48 EsMc intensity in Korean dark sleepers from Yugu-cheon (a branch of Geum-gang) in Gongju-si, Chungcheongnam-do. On the other hand, the endemicities of 2 ZTM, C. complanatum and M. orientalis, were very low in fishes from Soyangcheon in this study, when we compared with those of other regions [25].

Although more than 6 species of ZTM, i.e., C. sinensis, Metagonimus spp., C. armatus, Echinostoma spp., C. complanatum and M. orientalis, were detected in this study, their individual endemicities were generally not so high. However, the endemicities with CsMc in 2 fish species, P. herzi and S. variegatus wakive, were relatively high (422 and 254 CsMc PFI) in 2019, the last examination year. The endemicity of EsMc was also relatively high in Korean dark sleeper, O. platycephala, from Soyangcheon, in Wanju-gun, Jeollabuk-do, Korea. These particular epidemiological situations should be continuously checked to surveil the zoonotic trematode infections in the future.

\section{ACKNOWLEDGMENTS}

This study was supported by an Anti-Communicable Diseases Control Program, 2013 (Studies on the biological resources of human infecting trematodes and their larval infections in intermediate hosts), 2014 (Investigation of fishborne parasites and acquisition of their biological resources in the southern regions of Korea) and 2015 (Investigation of fishborne parasites and acquisition of their biological resources in the eastern regions of Korea) 2018 \& 2019 (Investigation and analysis on the infections of zoonotic trematode metacercariae in fish intermediate hosts in the Republic of Korea) of National Research Institute of Health (NRIH), Korea Centers for Disease Control and Prevention (KCDCP). We thank Jung-A Kim and Hee-Ju Kim, Department of Parasitology and Tropical Medicine, Gyeongsang National University College of Medicine, Jinju, Korea, for their help in fish examinations.

\section{CONFLICT OF INTEREST}

The authors have no conflicts of interest concerning the work reported in this paper.

\section{REFERENCES}

1. Korea Centers for Disease Control and Prevention. Korea Na $\neg$ tional Institute of Health. National Survey of the Prevalence of Intestinal Parasitic Infections in Korea, 2012. The 8th Report. 
Osong Chungcheongbuk-do, Korea, 2013.

2. Cho SH, Lee KY, Lee BC, Cho PY, Cheun HI, Hong ST, Sohn WM, Kim TS. Prevalence of clonorchiasis in southern endemic areas of Korea in 2006. Korean J Parasitol 2008; 46: 133-137. https://doi.org/10.3347/kjp.2008.46.3.133

3. Kim HK, Cheun HI, Chung BS, Lee KY, Kim TS, Lee SE, Lee WJ, Cho SH. Prevalence of Clonorchis sinensis infections along the five major rivers in Republic of Korea, 2007. Osong Public Health Res Perspect 2010; 1: 43-49. https://doi.org/10.1016/j.phrp.2010.12.010

4. June KJ, Cho SH, Lee WJ, Kim C, Park KS. Prevalence and risk factors of clonorchiasis among the populations served by primary healthcare posts along five major rivers in South Korea. Osong Public Health Res Perspect 2013; 4: 21-26. https://doi. org/10.1016/j.phrp.2012.12.002

5. Jeong YI, Shin HE, Lee SE, Cheun HI, Ju JW, Kim JY, Park MY, Cho $\mathrm{SH}$. Prevalence of Clonorchis sinensis infection among residents along 5 major rivers in the Republic of Korea. Korean J Parasitol 2016; 54: 215-219. https://doi.org/10.3347/kjp.2016.54.2.215

6. Cho SH, Sohn WM, Na BK, Kim TS, Kong Y, Eom K, Seok WS, Lee T. Prevalence of Clonorchis sinensis metacercariae in freshwater fish from three latitudinal regions of the Korean Peninsula. Korean J Parasitol 2011; 49: 385-398. https://doi.org/10.3347/ kjp.2011.49.4.385

7. Cho SH, Lee WJ, Kim TS, Seok WS, Lee TJ, Jeong KJ, Na BK, Sohn WM. Prevalence of zoonotic trematode metacercariae in freshwater fish from Gangwon-do, Korea. Korean J Parasitol 2014; 52: 399-412. https://doi.org/10.3347/kjp.2014.52.4.399

8. Sohn WM, Na BK, Cho SH, Lee SW, Choi SB, Seok WS. Trematode metacercariae in freshwater fish from water systems of Hantangang and Imjingang in Republic of Korea. Korean J Parasitol 2015; 53: 289-298. https://doi.org/10.3347/kjp.2015.53.3.289

9. Sohn WM, Na BK, Cho SH, Park MY, Kim CH, Hwang MA, No KW, Yoon KB, Lim HC. Prevalence of Clonorchis sinensis metacercariae in fish from water systems of Seomjin-gang (River). Korean J Parasitol 2017; 55: 305-312. https://doi.org/10.3347/kjp.2017.55.3.305

10. Yoon KB, Lim HC, Jeon DY, Park S, Cho SH, Ju JW, Shin SS, Na $\mathrm{BK}$, Sohn WM. Infection status with Clonorchis sinensis metacercariae in fish from Tamjin-gang (River) in Jeollanam-do, Republic of Korea. Korean J Parasitol 2018; 56: 183-188. https://doi. org/10.3347/kjp.2018.56.2.183

11. Sohn WM, Na BK, Cho SH, Ju JW, Son DC. Prevalence and intensity of Clonorchis sinensis metacercariae in freshwater fish from Wicheon stream in Gunwi-gun, Gyeongsangbuk-do, Korea. Korean J Parasitol 2018; 56: 41-48. https://doi.org/10.3347/kjp.2018.56.1.41

12. Sohn WM, Na BK, Cho SH, Ju JW. Infection status with Clonorchis sinensis metacercariae in fish from Yang-cheon (Stream) in Sancheong-gun, Gyeongsangnam-do, Korea. Korean J Parasitol 2019; 57: 145-152. https://doi.org/10.3347/kjp.2019.57.2.145
13. Sohn WM, Na BK, Cho SH, Lee HI, Lee MR, Ju JW. Kim GO. High endemicity with Clonorchis sinensis metacercariae in fish from Yongjeon-cheon (Stream) in Cheongsong-gun, Gyeongsangbukdo, Korea. Korean J Parasitol 2021; 59: 97-101. https://doi.org/10. 3347/kjp.2021.59.1.97

14. Sohn WM, Na BK, Cho SH, Kim CH, Hwang MA, No KW, Kim JD. Survey of zoonotic trematode metacercariae in fish from water systems of Geum-gang (River) in Republic of Korea. Korean J Parasitol 2021; 59: 23-33. https://doi.org/10.3347/kjp.2021.59.1.23

15. Sohn WM, Na BK, Cho SH Lee SW. Infection status with digenetic trematode metacercariae in fishes from coastal lakes in Gangwondo, Republic of Korea. Korean J Parasitol 2019; 57: 681-690. https:// doi.org/10.3347/kjp.2019.57.6.681

16. Sohn WM, Na BK. Infections with digenetic trematode metacercariae in freshwater fishes from two visiting sites of migratory birds in Gyeongsangnam-do, Republic of Korea. Korean J Parasitol 2019; 57: 273-281. https://doi.org/10.3347/kjp.2019.57.3.273

17. Mangyeong River in the list of rivers of Korea in Wikipedia - The free encyclopedia: http://en.wikipedia.org

18. Rhee JK, Baek BK, Lee SB, Koh HB. Epidemiological studies of Clonorchis sinensis in Mangyeong riverside areas in Korea. Korean J Parasitol 1983; 21: 157-166 (in Korean). https://doi.org/10.3347/ kjp.1983.21.2.157

19. Rhee JK, Lee HI, Baek BK, Kim PG. Survey on encysted cercariae of trematodes from freshwater fishes in Mangyeong riverside area. Korean J Parasitol 1983; 21: 187-192 (in Korean). https://doi.org/ 10.3347/kjp.1983.21.2.187

20. Kim IS, Kang EJ. Coloured fishes of Korea. Seoul, Korea. Academy Publishing Company. 1993, pp 1-477, (in Korean).

21. Sohn WM. Fish-borne zoonotic trematode metacercariae in the Republic of Korea. Korean J Parasitol 2009; 47 (suppl): 103-113. https://doi.org/10.3347/kjp.2009.47.S.S103

22. Sohn WM. Invertebrate Founa of Korea Vol. 6, No. 1. Trematodes. Incheon, Korea. The National Institute of Biological Resources. 2013, pp 1-125.

23. Sohn WM, Na BK, Cho SH, Ju JW, Kim CH, Yoon KB. Infection status with Metagonimus spp. metacercariae in fishes from Seomjin-gang and Tamjin-gang in Republic of Korea. Korean J Parasitol 2018; 56: 351-358. https://doi.org/10.3347/kjp.2018.56.4.351

24. Sohn WM, Na BK, Cho SH, Ju JW, Kim CH, Yoon KB, Kim JD, Son DC, Lee SW. Infections with Centrocestus armatus metacercariae in fishes from water systems of major rivers in Republic of Korea. Korean J Parasitol 2018; 56: 341-349. https://doi.org/10.3347/ kjp.2018.56.4.341

25. Sohn WM, Na BK, Cho SH. Infection status with Clinostomum complanatum metacercariae in fish from water systems of Nakdong-gang (River) in Korea. Korean J Parasitol 2019; 57: 389397. https://doi.org/10.3347/kjp.2019.57.4.389 
